\title{
Pigmented poroma with unusual location and dermatoscopic features
}

\author{
Luiza E. B. P. Kassuga, M.D. ${ }^{1}$, Thiago Jeunon, M.D. ${ }^{2,3}$, Maria Auxiliadora Jeunon Sousa, M.D. ${ }^{2}$, \\ Gabriella Campos-do-Carmo, M.D., ${ }^{4,5}$
}

\footnotetext{
${ }^{1}$ Fluminense Federal University-Niterói, Rio de Janeiro, Brazil

${ }^{2}$ ID-Investigação em Dermatologia, Rio de Janeiro, Brazil

${ }^{3}$ Departments of Dermatology and Pathology, Hospital Federal de Bonsucesso, Rio de Janeiro, Brazil

${ }^{4}$ Brazilian Society of Dermatology, Rio de Janeiro, Brazil

${ }^{5}$ National Institute of Cancer (INCA), Rio de Janeiro, Brazil
}

Key words: poroma, dermatoscopy, basal cell carcinoma, histopathology, pigmentation

Citation: Kassuga, LEBP, Jeunon T, Jeunon Sousa MA, Campos-do-Carmo G. Pigmented poroma with unsusual locatin and dermatoscopic features. Dermatol Pract Conc. 2012;2(3):7. http://dx.doi.org/10.5826/dpc.0203a07.

History: Received: January 12, 2012; Accepted: March 31, 2012;

Published: July 31, 2012

Copyright: (C2012 Kassuga et al. This is an open-access article distributed under the terms of the Creative Commons Attribution License, which permits unrestricted use, distribution, and reproduction in any medium, provided the original author and source are credited.

Funding: None.

Competing interests: The authors have no conflicts of interest to disclose.

All authors have contributed significantly to this publication.

Corresponding author: Gabriella Campos-do-Carmo, M.D., Av. Padre Leonel Franca 110 sala 304, Gávea, Rio de Janeiro, Brazil CEP: 22451-000.Tel/Fax.55.21.32649200.Email: dragabriellacampos@gmail.com.

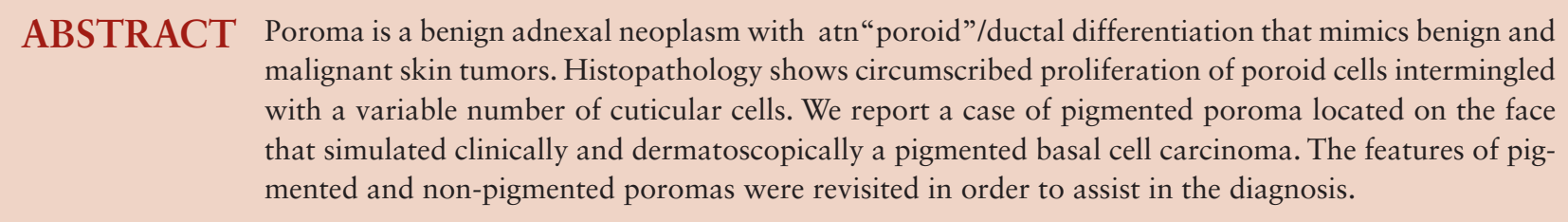

\section{Case report}

A previously healthy 38-year-old Caucasian female sought medical attention because of excoriated acne. A small, pigmented papule in the malar region of unknown duration was incidentally noted during physical examination (Figure 1). Dermatoscopy revealed some structures resembling brownish ovoid nests indicating the possibility of basal cell carcinoma
(BCC) (Figure 2). The lesion was completely excised and histopathology depicted a pigmented poroma (PP) characterized by epithelial aggregates of poroid and cuticular cells connected to the epidermis and extending into the dermis. The aggregates were regular in size and shape and exhibited formation of tubules and foci of necrosis en masse. Several neoplastic cells presented intracellular deposition of melanin, which was also present inside the tubules' lumina (Figures 3-6). 


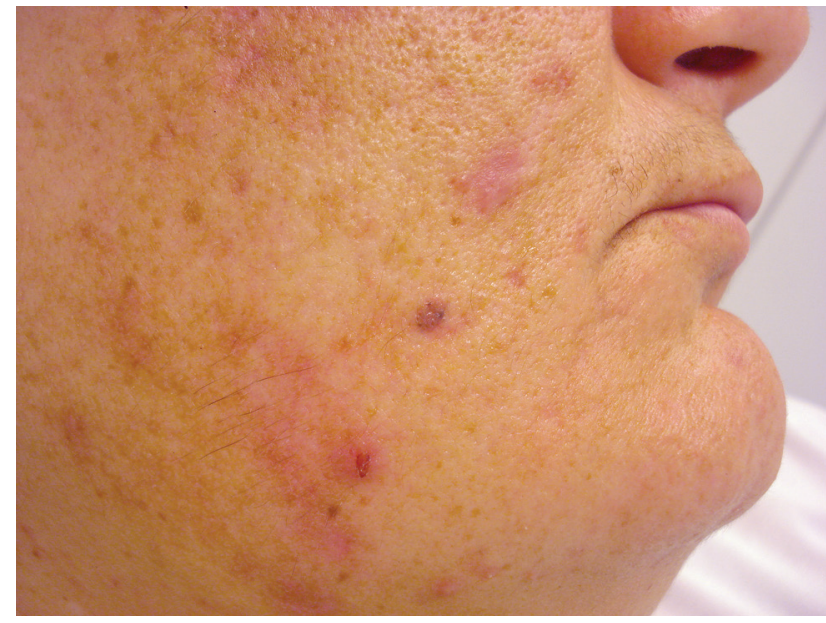

Figure 1. A brownish papule of $4 \mathrm{~mm}$ in diameter and some black points on the right malar region. [Copyright: (2012 Kassuga et al.]

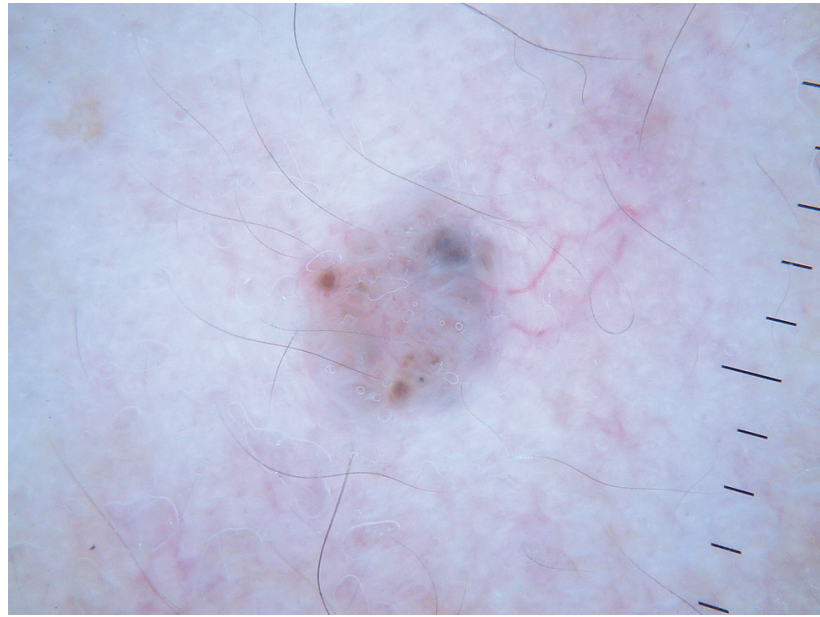

Figure 2. Presence of some ovoid nests (polarized dermoscopy 10X). [Copyright: @2012 Kassuga et al.]

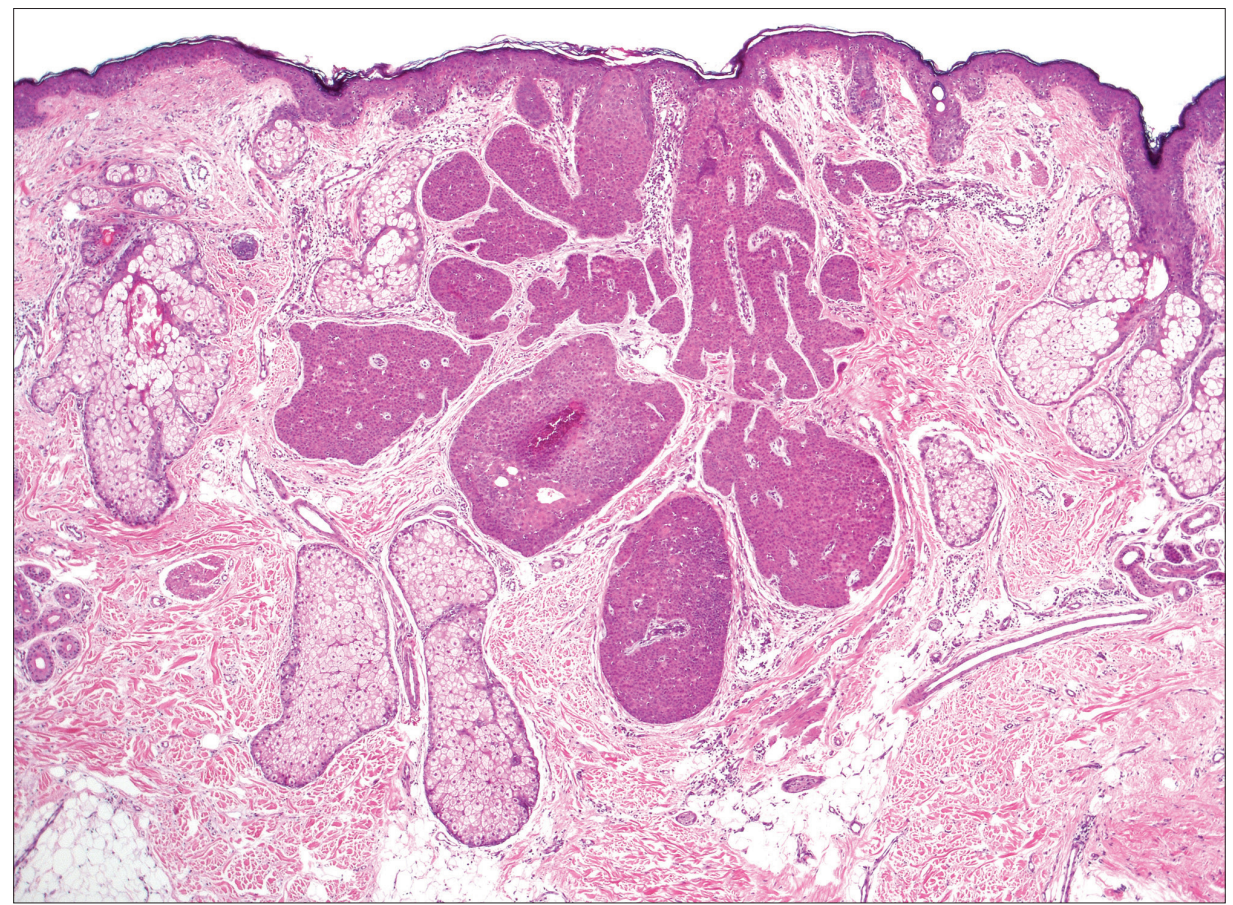

Figure 3. Pigmented poroma. Symmetrical and well-circumscribed epithelial neoplasm made up of cellular aggregates of regular sizes and shapes connected to the base of the epidermis and protruding into the dermis (HE, 40X). [Copyright: @2012 Kassuga et al.]

\section{Discussion}

Poroma was first described by Goldman et al in 1956 as a benign neoplasm originating from the sweat gland, made up of epithelial cells with eccrine differentiation [1]. Poromas are benign adnexal neoplasms with differentiation towards ductal epithelium of eccrine or apocrine glands $[1,2,3]$. Poromas represent $10 \%$ of all eccrine and apocrine neoplasms. Because ducts of both glands are morphologically identical under optical microscopy, the designation "poroma" is preferred over the term "eccrine poroma," which had been widely used. At least some cases of poroma with unequivocal evidence of apocrine differentiation had been previously reported [4].

The clinical features of poromas are variable, presenting usually as a slow growing, single and asymptomatic lesion, which may be a papule, a plaque or a nodule with a reddish hue. The surface may range from smooth to warty and ulceration occasionally comes into being. Slight tenderness is referred to in some cases [5]. Poromas affect mainly persons between the fifth and seventh decades of life and its typical location is the sole, although lesions on palms, head, neck or trunk had been found $[1,2,5,6,7]$. There is no predilection for gender or race. Multiple lesions are rare and this condition is known as poromatosis [5]. The etiopathogenesis is unclear and development of lesions over scar, radiation or trauma sites were reported [1,5]. Cases of PP have been sporadically reported, mostly in non-Caucasian patients [5,7]; it is estimated that pigmented lesions correspond to $17 \%$ of all cases of poromas [1,2]. Poromas may simulate clinically a large variety of benign and malignant neoplasms [5]. The 


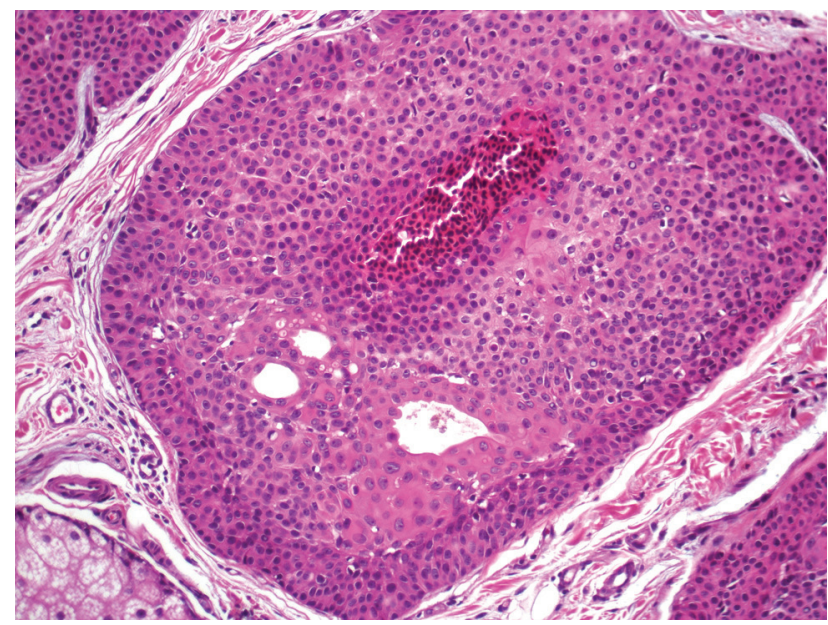

Figure 4. Pigmented poroma. Epithelial aggregate made up of poroid and cuticular cells. The poroid cells have small, round, uniform nuclei and scant cytoplasm and the cuticular cells display larger nuclei and abundant eosinophilic cytoplasm. Note the formation of ductal structures between the cuticular cells. Just above the center of the photomicrograph, there is a focus of necrosis en masse, characteristic of poromas (HE, 200X). [Copyright: @2012 Kassuga et al.]

differential diagnosis includes pyogenic granuloma, hemangioma, seborrheic keratosis, wart, fibroepithelial polyp, melanocytic nevus, cyst, BCC, squamous cell carcinoma and amelanotic melanomas [2,6].

Knowledge about the dermatoscopic features of pigmented and non-pigmented poromas is still limited. In regard to the dermatoscopic findings of non-pigmented poroma, Altamura et al described as characteristic features the presence of irregular reddish-milky areas, red lakes and irregular linear vessels depicted in a case that simulated an amelatotic melanoma [6]. Nicolino et al found similar features in dermatoscopy of non-pigmented poromas and suggested the designation of polymorphic vascular pattern (presence of more than one kind of vascular structure) [5]. This pattern could also be seen in squamous cell carcinomas, amelanotic melanomas and porocarcinomas. Ferrari et al analyzed seven cases of poroma and concluded that glomerular vessels and hairpin vessels were the most common vascular structures, followed by the irregular linear vessels, all of them surrounded by a pink-whitish halo. In this study, four of seven cases presented the polymorphic vascular pattern [2]. The dermatoscopic findings in two cases studied by Kue and Ohara, with the exception of spoke-wheel areas and leaf-like structures, were similar to those of pigmented BCC, i.e., bluish-gray dots, ovoid nests and arborizing vessels [8]. Minagawa and Koga examined twenty cases of PP and also found that pleomorphic vessels were the most frequent feature on dermatoscopy [7].

Histopathologically, poromas are made up of aggregates of round/coboidal poroid cells, which have small, uniform and round nuclei and scant cytoplasm, very similar to the cells that compound the external layer of excretory duct of

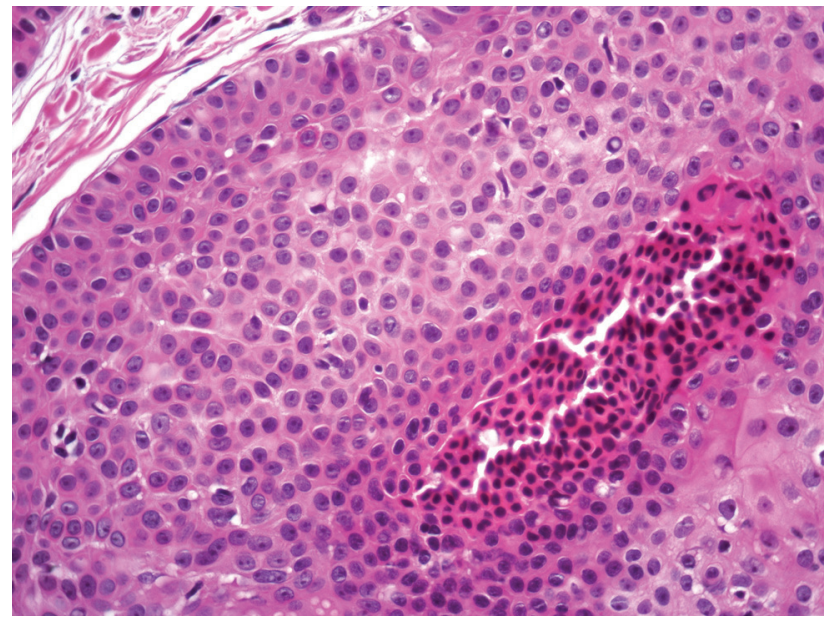

Figure 5. Pigmented poroma. Details of poroid cells (on the left) and of a focus of necrosis en masse (on the right). Note the absence of palisading of nuclei at the periphery of the aggregate (HE, 400X). [Copyright: @2012 Kassuga et al.]

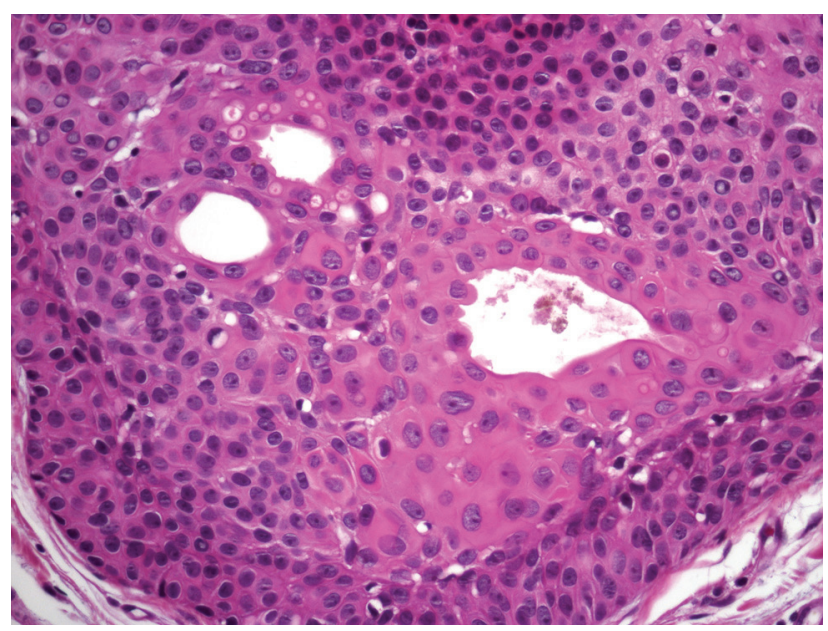

Figure 6. Pigmented poroma. Details of the cuticular cells at the center of the photomicrograph, between which there is formation of tubules. Note that inside one of the tubules, there are granules of melanin. At the periphery, poroid cells predominate (HE, 400X). [Copyright: @2012 Kassuga et al.]

the eccrine and the apocrine glands. The aggregates are connected to the base of the epidermis and project into the dermis, giving rise to large columns of uniform sizes and shapes. There might be a second population of cells, the cuticular cells, characterized by larger nuclei than the poroid cells and abundant eosinophilic cytoplasm. Those cells are reminiscent of the ones found in the inner layer of the eccrine/ apocrine duct. As a rule, there is formation of small ductal structures inside the neoplastic aggregates. In PP, melanin is present in the cytoplasm of neoplastic cells and, eventually, inside the tubules and in stromal melanophages. The stroma of poromas is highly vascularized and myxoid.

In the case of PP reported herein, the location of the lesion on the face in conjunction with the dermatoscopic findings showing structures very similar to ovoid nests made us believe the lesion could represent a BCC. As previously 
mentioned [8], PP may present dermatoscopic features in common with pigmented BCC, such as bluish-gray globules, ovoid nests and arborizing vessels. However, the arborizing vessels seen in pigmented poromas are less prominent and display fewer ramifications, in contrast to the typical arborizing vessels of BCC [1].

In conclusion, PP may mimic other benign and malignant skin tumors. It is important to consider the possibility of a $\mathrm{PP}$ in the differential diagnosis of pigmented lesions without criteria for a melanocytic proliferation. Nevertheless, considering the lack of established specific dermatoscopic criteria for poroma and that the polymorphic vascular pattern seen in poromas may also present in other malignant neoplasms of the skin, most cases of PP should be biopsied for histopathologic confirmation of the diagnosis.

\section{Acknowledgment}

We are indebted to the Dr. Alon Scope for his valuable insights, which contributed greatly to improving this article.

\section{References}

1. Avilés-Izquierdo JA, Velázquez-Tarjuelo D, Lecona-Echevarría M, Lázaro-Ochaita P. Dermoscopic features of eccrine poroma. Actas Dermosifiliogr. 2009;100(2):133-6.

2. Ferrari A, Buccini P, Silipo V, et al. Eccrine poroma: a clinical-dermoscopic study of seven cases. Acta Derm Venereol. 2009;89(2):160-4.

3. Aydingoz IE. New dermoscopic vascular patterns in a case of eccrine poroma. J Eur Acad Dermatol Venereol. 2009;23(6):725-6. Epub 2009 Feb 25.

4. Kurashige Y, Yamamoto T, Okubo Y, Tsuboi R. Poroma with sebaceous differentiation: report of three cases. Australas J Dermatol. 2010;51(2):131-4.

5. Nicolino R, Zalaudek I, Ferrara G, et al. Dermoscopy of eccrine poroma. Dermatology. 2007;215(2):160-3.

6. Altamura D, Piccolo D, Lozzi GP, Peris K. Eccrine poroma in an unusual site: a clinical and dermoscopic simulator of amelanotic melanoma. J Am Acad Dermatol. 2005;53(3):539-41.

7. Minagawa A, Koga H. Dermoscopy of pigmented poromas. Dermatology. 2010;221(1):78-83. Epub 2010 May 28.

8. Kuo HW, Ohara K. Pigmented eccrine poroma: a report of two cases and study with dermatoscopy. Dermatol Surg. 2003;29(10):1076-9. 